\title{
The Effect of Arginine Dietary Supplementation in Broiler Breeder Hens on Offspring Humoral and Cell-Mediated Immune Responses
}

http://dx.doi.org/10.1590/1516-635x160263-72

-Author(s)
Murakami AE'
Silva LMS da'
Fernandes JIM"
Silveira TGVII'
Garcez Neto AF"
| Department of Animal Science, State Uni-
versity of Maringa, 87020-900, Parana,
Brazil.
" Laboratory of Poultry Experimentation, Fe-
deral University of Parana, Campus Paloti-
na, 85950-000, Parana, Brazil.
"I Department of Clinical Analyses, State
University of Maringa, 87020-900, Parana,
Brazil.
Iv Laboratory of Animal Nutrition, Federal
University of Parana, Campus Palotina,
85950-000, Parana, Brazil.

mail Adress

Corresponding author e-mail address:

J. I. M. Fernandes

Universidade Federal do Paraná - Campus

Palotina, Rua Pioneiro, 2153, Jardim

Dallas, CEP 85950-000, Palotina-Paraná

Phone +55 4432118525

Mobile +55 4499643113

Email: jimfernandes@ufpr.br

\section{nKeywords}

Arginine, macrophage, maternal diet, offspring immunity.

\section{ABSTRACT}

The influence of supplementing the diet of broiler breeder hens with arginine (Arg) on their offspring's humoral and cell-mediated immune response was evaluated in two experiments. In experiments I and II, breeder hens were fed diets containing graded levels of Arg (0.943, $1.093,1.243,1.393$ and $1.543 \%$ digestible Arg). In experiment I, the offspring was randomly grouped according to the treatment received by the breeder hens, with five levels of Arg in the maternal diet and six replicates, giving a total 30 experimental units. In experiment II, the offspring were grouped in accordance with the treatment received by the breeder hens; however, Arg was added to the starter diet (1.300, 1.450, 1.600, 1.750 and 1.900\% digestible Arg) and also the growing diet $(1.150,1.300,1.450,1.600$ and $1.750 \%$ digestible Arg). Supplementation of the broiler breeder hen diet did not influence ( $p>0.05$ ) the development of the lymphoid organs (cloacal bursa, thymus and spleen) of the offspring, whether their diet were supplemented or not. Nevertheless, greater weight and dimensions cloacal bursa were found in the supplemented offspring in comparison with the nonsupplemented offspring. Macrophage phagocytic activity was found to be unaffected ( $p>0.05)$, independently of the Arg supplementation. The offspring fed with supplemented diets showed a linear reduction in the antibody titer against Newcastle Disease $(p<0.05)$ at seven days of age, and a quadratic response $(p<0.05)$ at 28 days of age. The antibody titer in the non-supplemented offspring was not influenced ( $p>0.05)$ by the breeder hen diet. This study concluded that supplementing the breeder hen diet with arginine is insufficient to improve the humoral and cellular immune response, requiring supplementation of the offspring diet.

\section{INTRODUCTION}

The immune system of birds differs from that of mammals in certain aspects, particularly with regard to the structure and differentiation of the lymphoid organs (Jeurissen, et al., 1994), which development begins during the embryonic life and continues after hatching. The last hours of incubation and the first days of post-hatching life are fundamental for this development to complete. Chickens are only able to produce their own immunoglobulins after the second week of life (Smith et al., 1994). Consequently, all of the maternal immunoglobulins required to protect the chick must be present in the egg and be transported from the egg yolk across the yolk sac in order to be present in the circulation of the newly-hatched chick (Brambelt, 1969; Tressler \& Roth, 1987). This is the only defence mechanism the neonate has against the external environment after hatching. 
Although it is known that maternal nutrition affects the immunocompetence of offspring (Uni \& Ferket, 2004), the effect of nutrients has been explored more fully in broiler chickens than in broiler breeder hens. Nutritional programmes for broiler chickens have evolved alongside the intense genetic improvement of modern broiler chicken strains. The combination of the short interval between generations and the pressure of the poultry industry for economic efficiency has driven genetic improvement programs to change the conformation of chickens and, consequently, their nutritional requirements.

The requirements of broiler breeder hens for specific immunomodulatory nutrients and their impact on the health, and consequently the production of broiler chickens, also need to be continually reviewed because of the rapid genetic changes (Calini \& Sirri, 2007).

Amino acids, in addition of being constituent biomolecules of proteins and peptides in all living organisms, are precursors of many nitrogen compounds performing important physiological functions. Arginine (Arg) is considered an essential amino acid for poultry, especially during the starter phase, because chicks do not have a functional urea biochemical cycle, are unable to synthesize Arg, and, consequently, require this amino acid to be supplied in the diet. Poultry present the highest demand for Arg among the species of animals studied by Ball et al. (2007), because, in addition of lacking endogenous synthesis, there is a high rate of protein deposition due to the rapid growth of modern broiler lines and to the antagonism of Arg with lysine (Lys)

The negative effect of the antagonism between Arg and Lys on the requirement for Arg for growth and meat and egg is not as marked as its metabolic demand acid (Harper et al., 1970). Arginine is required for the synthesis of several compounds, such as ornithine, polyamines, proline, creatine, proteins, nitric oxide (NO) and citrulline, and it is also considered a powerful secretagogue, increasing the release of insulin, growth hormone $(\mathrm{GH})$ and insulin-like growth factor (IGF-I) into the blood stream (Newsholme et al., 2005). This action is a consequence of the rapid depolarization of the cell membrane associated with the transport of amino acids with positive side chains.

Immune-stimulated animals may have an increased need for Arg due to its conversion into ornithine and production of polyamines, which play a key role in cell division, DNA synthesis and cell cycle regulation (Löser et al., 1999; Le Floc'h et al., 2004). Arginine acts as a potent modulator of phagocytosis mediated by macrophages through the synthesis of $\mathrm{NO}$ (Hibbs et al., 1987; Amber et al., 1991; Tsai et al., 2002), which stimulates local vasodilation and promotes tissue repair (Bredt and Snyder, 1994). Arginine is also one of the factors required for the differentiation and release of B lymphocytes from the bone marrow (Jonge et al., 2002) and has a stimulatory effect on the production and activity of cytokines and other immune system cells (Ochoa et al., 2001; Wu et al., 2009).

However, the immunomodulatory effects of Arg in maternal diets need to be evaluated considering the immune response of the offspring. Under adverse conditions of different nature and magnitude, environmental challenges during the first weeks after hatching can cause varying degrees of immunosuppression in broiler chickens (Munir et al., 2009).

The objective of this study was to evaluate the influence of arginine supplementation in the maternal diet on the cell-mediated and humoral immune response of the offspring, fed with or not supplemented with Arg.

\section{MATERIALS AND METHODS}

Five maternal diets were formulated with increasing levels of supplemental L-Arginine (0, 150, 300, 450, or $600 \mathrm{mg} / \mathrm{kg}$ of maternal diet), equivalent to the levels of $0.943,1.093,1.243,1.393$ and $1.543 \%$ of digestible Arg. Each diet was fed to six replicates of 12 females and 1 male Ross 390 broiler breeders. The experimental period started when birds were 25 weeks old, when the breeding stock reached $5 \%$ production. Between weeks 31 and 32, all eggs laid were stored for incubation. Approximately 530 eggs were obtained per treatment, totaling 2650 eggs, which were transported to a commercial hatchery for incubation. After hatching, chicks were selected and transported to the Iguatemi Experimental Farm at State University of Maringá and housed in experimental broiler house.

\section{Experiment I}

A total of 1050 chicks, with $41.22 \mathrm{~g}$ average mean initial body weight, were randomly selected and housed according to breeder treatments. There were six replicates of 35 birds for each of the five levels of L-Arginine fed to the breeders, totaling 30 experimental units. Chicks were fed a single feed, with no Arg supplementation, to investigate the effect of Arg supplementation to breeder diets on the performance of the offspring.

During the starter phase, chick feeders and drinkers were used up to five days of age, and then were 
gradually substituted by tubular feeders and automatic bell drinkers. Each pen had a round protective barrier and a brooder as a source of warmth for the chicks. A continuous light program during the day was adopted for the first ten days and 23 hours of light/day for the remaining experimental period. Feed and water were supplied ad libitum throughout the experimental period.

Mortality was recorded and the birds and the feed residues were simultaneously weighed to correct feed intake and feed conversion ratio.

A two-phase feeding program was applied: a starter phase ( 1 to 21 days of age) and a grower-finisher phase ( 22 to 42 days of age). The experimental diets, based on corn and soybean meal, were formulated to contain $20.0 \% \mathrm{CP}, 2,947.19 \mathrm{ME} \mathrm{kcal} / \mathrm{kg}, 1.240 \%$ Lys, $1.300 \%$ Arg, for the starter phase, and $18.50 \%$ CP; $3,170 \mathrm{ME} \mathrm{kcal} / \mathrm{kg}, 1.100 \%$ Lys, and $1.150 \%$ Arg, for the grower-finisher phase.

\section{Experiment II}

A total of 960 chicks, with $41.52 \mathrm{~g}$ average initial body weight, were randomly selected and housed, there being six replicates of 32 birds each for the five levels of L-Arginine maternal diet, making a total of 30 experimental units. Experimental diets, starter phase and a growing and finishing phase, were developed with added L-Arginine (0, 150, 300, 450, $600 \mathrm{mg} /$ $\mathrm{kg}$ ) to the basal diets as a replacement of the inert component. The digestible Arg dietary levels of the starter diet (1-21 days) were 1.300, 1.450, 1.600, 1.750, and $1.900 \%$, and of the grower-finisher diet (22-42 days) were $1.150,1.300,1.450,1.600$, and $1.750 \%$ (Table 1). The experimental diets were formulated in accordance with the feed chemical composition values and nutritional recommendations of Rostagno et al. (2005) and were similar to the diets in experiment I, except for different Arg levels in replacement of the inert material.

The experimental management was as described for the previous experiment.

\section{Blood Collection and Vaccine Antibody Titer Analysis}

Blood samples were collected from two birds per replicate, at 7 days of age, before vaccination, and then on days $14,21,28$, and 35 . Chicks were vaccinated against Newcastle disease (Zoetis ${ }^{\circledR}$ ) with a $0.3 \mathrm{~mL}$ intraocular dose per bird at 7 and 21 days of age. Serum antibody titer against the Newcastle Disease virus was evaluated using the immunoenzymatic test (ELISA-test). The analyses were performed using a
Table 1 - Composition of the experimental feeds fed to the offspring of broiler breeders fed diets with different levels of supplemental arginine.

\begin{tabular}{lcc}
\hline Ingredients & $1-21$ days of age & $22-42$ days of age \\
Corn & 64.58 & 65.67 \\
\hline Soybean meal & 30.07 & 26.95 \\
\hline Soybean oil & 0.19 & 3.20 \\
\hline Dicalcium phosphate & 1.85 & 1.49 \\
\hline Calcitic limestone & 0.77 & 0.77 \\
\hline Sodium Bicarbonate & 0.41 & - \\
\hline Common salt & 0.30 & 0.30 \\
\hline Inert material (kaolin) & 0.70 & 0.70 \\
\hline DL-Methionine, 98\% & 0.35 & 0.28 \\
\hline L-Lysine HCl, 78\% & 0.45 & 0.37 \\
\hline L-Threonine, 98\% & 0.18 & 0.12 \\
\hline Mineral supplement ${ }^{2}$ & 0.05 & 0.05 \\
\hline Vitamin supplement, & 0.10 & 0.10 \\
\hline Total & 100.00 & 100.00 \\
\hline Calculated values & & \\
\hline CP (\%) & 20.00 & 18.50 \\
\hline ME (kcal/kg) & 2,947 & 3,170 \\
\hline Met + Cys, dig (\%) & 0.890 & 0.790 \\
\hline Lysine, dig (\%) & 1.240 & 1.100 \\
\hline Tryptophan, dig (\%) & 0.230 & 0.193 \\
\hline Threonine, dig (\%) & 0.810 & 0.710 \\
\hline Arginine, dig (\%) & 1.30 & 0.150 \\
\hline Calcium (\%) & 0.870 & 0.770 \\
\hline Available Phosphorous (\%) & 0.450 & 0.380 \\
\hline Sodium (\%) & 0.270 & 0.157 \\
\hline Chlorine (\%) & 0.214 & 0.214 \\
\hline Supmento min & \\
\hline
\end{tabular}

Suplemento mineral $\circledast$ (Content per $\mathrm{kg}$ of premix): Iron 100,000 mg, Copper 16,000 mg, lodine 2,400 mg, Zinc 100,000 mg, Manganese 140,000 mg, Selenium $400 \mathrm{mg}$, Vehicle q.s.p. 1,000 g.

${ }^{2}$ Suplemento Vitamínico Inicial ${ }^{8}$ (Content per kg of premix): Vit. A 7,000,000 UI, Vit. D3 2,200,000 UI, Vit. E 11,000 mg, Vit. K3 1,600 mg, Vit. B1 2,000 mg, Vit. B2 5,000 mg, Vit. B12 12,000 mcg, Vit. B6 3,000 mg, Niacin 35,000 mg, Pantothenic Acid 13,000 mg, Folic Acid 800 mg, Antioxidant 100,000 mg, Vehicle q.s.p. 1,000g.

${ }^{3}$ Suplemento Vitamínico Crescimento ${ }^{\circledR}$ (Content per kg of premix): Vit. A 6,000,000 UI, Vit. D3 2,000,000 UI, Vit. E 10,000 mg, Vit. K3 1,600 mg, Vit. B1 1,400 mg, Vit. B2 4,000 mg, Vit. B12 10,000 mcg, Vit. B6 2,000 mg, Niacin 30,000 mg, Pantothenic Acid 11,000 mg, Folic Acid 600 mg, Antioxidant 100,000 mg, Vehicle q.s.p. 1,000 g.

commercial ELISA kit (Enzyme Linked Immuno Sorbent Assay), manufactured by Laboratório Idexx®, and the obtained data were expressed as absorbance values. The antibody titer data evaluated by ELISA were converted to $\log 10$.

\section{Histomorphometric Analysis}

On days 7 and 21, the thymus, cloacal bursa, spleen and liver of two birds per replicate were collected, totaling 12 birds per treatment. Birds were previously shock-stunned and then bled. After sacrifice, birds were individually weighed and their carcasses dissected for removal of the lymphoid organs (thymus, spleen, and cloacal bursa). The lymphoid organs were weighed immediately after the dissection and removal of the 

Broiler Breeder Hens on Offspring Humoral and CellMediated Immune Responses

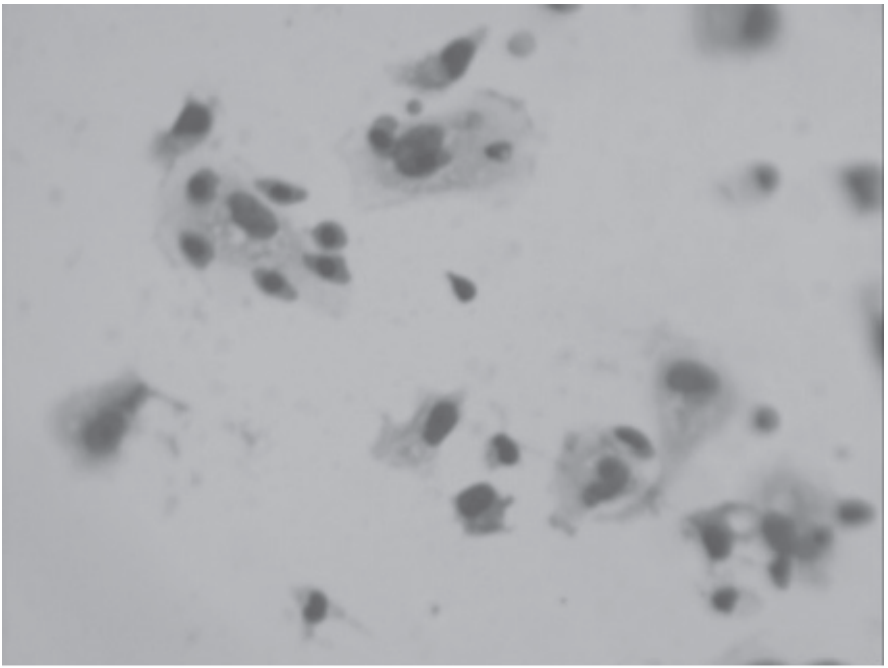

Figure 01. Macrophages with phagocytized erythrocytes

exogenous tissue. The collected organs were weighed using a precision scale and organ weight relative to live weight was calculated.

Lymphoid follicles, cloacal bursa, and the liver were placed in flasks containing $10 \%$ buffered formalin solution. Cross sections were then cut from the center of the cloacal bursa at $7 \mu \mathrm{m}$ thickness and stained using the hematoxylin and eosin (HE) method. Slides were scanned using a "HP ScanJet II v.2.5 scanner" and the images were processed using "Paint Shop Pro v.5.0" software. Images were scanned at brilliance between 125 and 145, contrast 185, and scale of $800 \%$. Images were saved with jpg extension and transferred to the image analyzer. The computerized image analyzer IMAGE PROPLUS 5.2 from Mídia Cibertecnics was used to read the images. The heights of three lymphoid tissue folds from each replicate (12 birds per treatment) were measured and their mean calculated.

The presence of lymphoid clusters in the liver samples was analyzed. Slides with liver sections were scanned lengthwise and lymphoid clusters were quantified using an optical microscope at 10X magnification (Olympus BH2 Olympus America INC., NY, USA).

\section{Phytohemagglutinin (PHA)}

At 35 days of age, two birds per replicate in experiment II only, totaling 12 birds per treatment, were identified with numbered rings and used to evaluate cell-mediated immunity in vivo (Corrier \& DeLoach, 1990). Each bird was intradermally inoculated in the interdigital space between the $3^{\text {rd }}$ and $4^{\text {th }}$ toe of the right foot with $0.1 \mathrm{~mL}$ of a phytohemagglutinin solution (PHA-M®, 1057601, Invitrogen). As negative control, $0.1 \mathrm{~mL}$ of sterile saline solution was inoculated between the $3^{\text {rd }}$ and $4^{\text {th }}$ toe of the left foot. The skin thickness of the skin of both feet was measured in millimeters before inoculation, and 3, 6, 12 and $24 \mathrm{~h}$ after inoculation, using a digital micrometer. Reaction was calculated (Corrier and De Loach, 1990) as: Reaction phytohemagglutinin = response minus control response, in which phytohemagglutinin response is given by skin thickness after the inoculation time minus skin thickness at time zero (before inoculation). The control response is given by skin thickness after the inoculation (saline solution) time minus skin thickness at time zero (before inoculation).

\section{Evaluation of Macrophage Phagocytic Activity}

Macrophage phagocytic activity was evaluated in two birds per replicate totaling four birds per treatment. Birds from those fed the diet supplemented with graded digestible Arg levels were inoculated on day 35 by intra-abdominal injection of Sephadex G-50® (Sigma) at 3\%, (1.0 mL/100g of live weight; Qureshi et al., 1986; Gore and Qureshi, 1997; Konjufca, 2004).

G-14 intravascular catheters were used for this procedure. After $42 \mathrm{~h}$, the birds were stunned by electronarcosis and sacrificed by cervical dislocation, washed (neutral detergent) and sterilized (70\% alcohol). Birds were then transported to the laboratory, where their abdominal cavity was opened and washed with $20 \mathrm{~mL}$ of sterile PBS solution containing $0.5 \mathrm{IU}$ heparin/L (Liquemine ${ }^{\circledR}$ 25,000 IU/5mL, Roche).

Pasteur pipettes were used to collect approximately $15 \mathrm{~mL}$ of abdominal liquid, which was immediately transferred to Falcon test tubes in an ice bath. The material was centrifuged at $1500 \mathrm{rpm}$ for $10 \mathrm{~min}$ and the pellet was re-suspended in $2 \mathrm{~mL}$ of RPMI $1640 \AA$ medium (Sigma). A volume of $150 \mu \mathrm{L}$ of this suspension was added to each well of a culture plate ( 24 wells) and covered with $13-\mathrm{mm}$ diameter coverslips for incubation at ambient temperature for $1 \mathrm{~h}$. The plate was washed with cold sterile PBS to remove non-adherent cells. A volume of $150 \mu \mathrm{L}$ of the suspension was then added to $3 \%$ sheep erythrocytes in RPMI 1640® medium (Sigma) and was incubated at ambient temperature at 5\% carbon dioxide for $1 \mathrm{~h}$. The non-adherent erythrocytes were washed out with cold sterile PBS. Next, staining was performed using a commercial kit (Panótico Rápido LB®, Laborclin).

The coverslips were mounted after $24 \mathrm{~h}$ using Permount $\circledast$. On each slide, 300 macrophages and the 
number of these cells with phagocytized erythrocytes were counted. Phagocytic activity was calculated from the number of macrophages containing phagocytized erythrocytes divided by the total number of macrophages counted.

The data obtained for each parameter were decomposed into orthogonal polynomials to enable variance and regression analyses, depending on their distribution, using the SAEG statistics programme (UFV, 1997).

The determination coefficients were calculated as the percentage of sum of squares of the model relative to the total sum of squares. The antibody titer data evaluated by ELISA were converted to $\log 10$.

\section{RESULTS AND DISCUSSION}

Average lymphoid organ weights of the broiler chickensfed with supplemented and non-supplemented diets are given in Table 2. Arg supplementation in broiler breeder diets did not influence the development of the lymphoid organs of the offspring fed diets supplemented or not with Arg ( $p>0.05)$.

The thymus and cloacal bursa are primary lymphoid organs and sites of $T$ and $B$ lymphocyte maturation, respectively. These organs are of fundamental importance for bird development during the post- hatching period, and suffer gradual physiological involution as sexual maturity nears (Morgullis, 2002).

In the context of the development and maturation of the lymphoid organs, studies with mammals have shown that the immune response may be influenced by dietary Arg (Kennedy et al., 1994; Kobayashi et al., 1998; Lewis \& Langkamp-Henken, 2000). Experiments with young animals have demonstrated thyrotrophic effects of the supplementation with L-Arg, such as an increase in thymus weight and in the number and functional reactivity of thymic lymphocytes. The expression of immunoestimulatory effects is stronger in stressed or immunosuppressed animals.

According to Kidd (2004), beneficial effects were observed when Arg was supplemented at levels 25 and $50 \%$ higher than the established nutritional requirements. Levels close to those recommended did not improve humoral or cell-mediated immune response, despite raising Arg blood levels (Kidd, 2004).

Contrary to the results observed in the present experiments, Jahanian (2009) observed that starter broilers phase fed diets supplemented with Arg and containing low protein levels presented heavier thymus, indicating that development of the lymphoid organs may be impaired only when Arg is deficient.

The comparison of lymphoid organ weights of the birds that fed diets supplemented with Arg with those

Table 2 - Means and standard deviations of the relative weights (\%) of the lymphoid organs of broiler breeder offspring fed diets supplemented or not with arginine.

\begin{tabular}{|c|c|c|c|c|c|c|}
\hline \multirow{3}{*}{ Arg maternal diet (\%) } & \multicolumn{6}{|c|}{ Offspring - non-supplemented } \\
\hline & \multicolumn{2}{|c|}{ Thymus* (\%) } & \multicolumn{2}{|c|}{ Cloacal bursa* (\%) } & \multicolumn{2}{|c|}{ Spleen* (\%) } \\
\hline & 7 days & 21 days & 7 days & 21 days & 7 days & 21 days \\
\hline 0.943 & $0.58 \pm 0.03$ & $0.54 \pm 0.04$ & $0.15 \pm 0.011$ & $0.24 \pm 0.01$ & $0.06 \pm 0.005$ & $0.11 \pm 0.01$ \\
\hline 1.093 & $0.55 \pm 0.03$ & $0.56 \pm 0.05$ & $0.17 \pm 0.010$ & $0.22 \pm 0.02$ & $0.08 \pm 0.008$ & $0.11 \pm 0.01$ \\
\hline 1.243 & $0.56 \pm 0.03$ & $0.57 \pm 0.03$ & $0.16 \pm 0.014$ & $0.21 \pm 0.01$ & $0.12 \pm 0.036$ & $0.09 \pm 0.01$ \\
\hline 1.393 & $0.52 \pm 0.04$ & $0.57 \pm 0.04$ & $0.15 \pm 0.014$ & $0.21 \pm 0.04$ & $0.07 \pm 0.007$ & $0.10 \pm 0.01$ \\
\hline 1.543 & $0.52 \pm 0.03$ & $0.51 \pm 0.05$ & $0.13 \pm 0.010$ & $0.21 \pm 0.03$ & $0.09 \pm 0.016$ & $0.11 \pm 0.01$ \\
\hline CV (\%) & 13.81 & 17.49 & 19.15 & 18.36 & 51.79 & 24.09 \\
\hline \multirow[t]{2}{*}{ Effect } & NS & NS & NS & NS & NS & NS \\
\hline & \multicolumn{6}{|c|}{ Offspring - supplemented } \\
\hline \multirow[t]{2}{*}{ Arg offspring diet (\%) } & \multicolumn{2}{|c|}{ Thymus (\%) } & \multicolumn{2}{|c|}{ Cloacal bursa (\%) } & \multicolumn{2}{|c|}{ Spleen (\%) } \\
\hline & 7 days & 21 days & 7 days & 21 days & 7 days & 21 days \\
\hline 1.300 & 0.53 & 0.56 & 0.16 & 0.25 & 0.07 & 0.08 \\
\hline 1.450 & 0.57 & 0.57 & 0.15 & 0.20 & 0.09 & 0.10 \\
\hline 1.600 & 0.59 & 0.59 & 0.18 & 0.22 & 0.08 & 0.09 \\
\hline 1.750 & 0.51 & 0.48 & 0.19 & 0.26 & 0.08 & 0.11 \\
\hline 1.900 & 0.58 & 0.53 & 0.15 & 0.23 & 0.07 & 0.10 \\
\hline CV (\%) & 18.59 & 18.14 & 17.92 & 20.81 & 21.76 & 22.98 \\
\hline Effect & NS & NS & NS & NS & NS & NS \\
\hline
\end{tabular}

$\mathrm{CV}$ : coefficient of variation, $\mathrm{NS}=(p>0.05)$, ${ }^{*}$ relative to live weight 
receiving the non-supplemented diet (Table 3) shows the influence of Arg supplementation on cloacal bursa weight in the starter $(p<0.05)$. The observed increase is very important as the cloacal bursa is the main maturation site of B lymphocytes, which are essential for the immune response. In the phase of 1 to 7 days of age, this increase may reflect an improvement of the immune status, since health challenges in this period may compromise the performance of birds until the end of the rearing period. De Jonge et al. (2002) demonstrated in mammals that Arg is one of the factors required for the differentiation and release of $B$ lymphocytes from the bone marrow, which function is analogous to the cloacal bursa in poultry.

Table 3 - Means and standard deviation of the relative weights (\%) of the lymphoid organs, thymus, spleen and cloacal bursa in the experiment conducted on the offspring of 7 and 21 days of age with non-supplemented diets and progeny diets supplemented with graded levels of Arg.

\begin{tabular}{lccc}
\hline & \multicolumn{3}{c}{7 days } \\
\cline { 2 - 4 } & Thymus (\%) & $\begin{array}{c}\text { Cloacal bursa } \\
(\%)\end{array}$ & Spleen (\%) \\
\hline Offspring non-supplemented & $0.54^{\mathrm{a}} \pm 0.01$ & $0.15 \pm 0.005^{\mathrm{b}}$ & $0.085^{\mathrm{a}} \pm 0.008$ \\
Offspring supplemented & $0.56^{\mathrm{a}} \pm 0.02$ & $0.17 \pm 0.006^{\mathrm{a}}$ & $0.079^{\mathrm{a}} \pm 0.003$ \\
\hline CV (\%) & 0.02 & 0.05 & 0.06 \\
\hline & \multicolumn{3}{c}{21 days } \\
\cline { 2 - 4 } & Thymus (\%) & $\begin{array}{c}\text { Cloacal bursa } \\
(\%)\end{array}$ & Spleen (\%) \\
\hline Offspring non-supplemented & $0.55^{\mathrm{a}} \pm 0.01$ & $0.22^{\mathrm{a}} \pm 0.007$ & $0.11^{\mathrm{a}} \pm 0.005$ \\
Offspring supplemented & $0.54^{\mathrm{a}} \pm 0.02$ & $0.23^{\mathrm{a}} \pm 0.009$ & $0.09^{\mathrm{a}} \pm 0.004$ \\
CV (\%) & 0.02 & 0.08 & 0.04 \\
\hline CV: coffient
\end{tabular}

$\mathrm{CV}$ : coefficient of variation ${ }^{\mathrm{a}, \mathrm{b}}$ Means within columns with the same superscript are not significantly different $(p<0.05)$.
The count of lymphoid clusters in the liver and the histomorphometry of the cloacal bursa were not affected $(p>0.05)$ by Arg supplementation (Table 4). However, when the results of these analyses are compared between birds fed Arg-supplemented diets with those that received non-supplemented diets (Table 5), significant differences were observed at 7 days of age $(p<0.05)$. Birds that did not receive Arg supplementation in their diet, but derived from breeders fed Arg-supplemented diets, showed higher number of lymphoid clusters in comparison to birds that received supplemented diets. In addition, the histomorphometric values of the cloacal bursa were also higher in these birds. At 21 days, there were no significant differences.

The formation of lymphoid clusters in the liver is an alternative route for inducing cell-mediated immunity. Although these structures are insufficient to enable the differentiation and maturation of antibodies, they provide additional sites for initiating the cell-mediated immune response (Leavy, 2009).

In addition, there is a direct relationship between the liver and the cloacal bursa. In poultry, B lymphocytes, which are responsible for the production of the antibodies involved in the humoral immune response, are produced in the embryonic liver, yolk sac and bone marrow during the first phase of incubation. These lymphocytes then migrate to the cloacal bursa, where they mature and differentiate for up to ten weeks, after which they leave to colonize other organs, such as the spleen and the Harder gland (Butcher \& Miles, 2003).

Table 4 - Means and standard deviations of the lymphoid clusters in the liver and the histomorphometry measurements of the cloacal bursa (mm) of supplemented and non-supplemented offspring of broiler breeder hens fed diets with graded levels of Arg.

\begin{tabular}{|c|c|c|c|c|}
\hline \multirow{2}{*}{ Arg in the maternal diet (\%) } & \multicolumn{2}{|c|}{ Lymphoid clusters } & \multicolumn{2}{|c|}{ Histomorphometry cloacal bursa } \\
\hline & 7 days & 21 days & 7 days & 21 days \\
\hline 0.943 & $1.05 \pm 0.10$ & $1.96 \pm 0.41$ & $14.43 \pm 0.97$ & $32.47 \pm 1.98$ \\
\hline 1.093 & $0.98 \pm 0.28$ & $1.37 \pm 0.21$ & $13.94 \pm 2.25$ & $30.66 \pm 2.40$ \\
\hline 1.243 & $0.77 \pm 0.04$ & $1.78 \pm 0.29$ & $15.03 \pm 0.60$ & $30.42 \pm 1.09$ \\
\hline 1.393 & $0.80 \pm 0.15$ & $1.70 \pm 0.43$ & $14.49 \pm 0.68$ & $31.12 \pm 1.87$ \\
\hline 1.543 & $0.96 \pm 0.18$ & $2.32 \pm 0.37$ & $14.64 \pm 1.49$ & $32.22 \pm 1.95$ \\
\hline$C V(\%)$ & 43.98 & 47.08 & 5.63 & 9.15 \\
\hline Effect & NS & NS & NS & NS \\
\hline \multirow{2}{*}{ Arg in the offspring diet (\%) } & \multicolumn{2}{|c|}{ Lymphoid clusters } & \multicolumn{2}{|c|}{ Histomorphometry cloacal bursa } \\
\hline & 7 days & 21 days & 7 days & 21 days \\
\hline 1.300 & $0.76 \pm 0.10$ & $1.68 \pm 0.35$ & $19.36 \pm 2.06$ & $35.35 \pm 1.91$ \\
\hline 1.450 & $0.49 \pm 0.15$ & $2.16 \pm 0.41$ & $18.65 \pm 0.22$ & $40.27 \pm 12.44$ \\
\hline 1.600 & $0.72 \pm 0.24$ & $1.89 \pm 0.22$ & $20.35 \pm 0.64$ & $33.31 \pm 0.36$ \\
\hline 1.750 & $0.53 \pm 0.05$ & $1.92 \pm 0.36$ & $21.95 \pm 1.39$ & $44.87 \pm 15.40$ \\
\hline 1.900 & $0.53 \pm 0.12$ & $2.13 \pm 0.25$ & $19.05 \pm 1.28$ & $25.62 \pm 1.11$ \\
\hline$C V(\%)$ & 58.07 & 41.41 & 4.73 & 53.59 \\
\hline Effect & NS & NS & NS & NS \\
\hline
\end{tabular}

CV: coefficient of variation, NS $=(p>0.05)$ 
Table 5 - Means and standard deviations of the lymphoid cultures in the liver and the histomorphometric measurements of the cloacal bursa $(\mathrm{mm})$ from the experiments conducted with offspring of 7 and 21 days of age with non-supplemented diets and diets supplemented with graded levels of Arg.

\begin{tabular}{lcc}
\hline & $\begin{array}{c}\text { Lymphoid } \\
\text { clusters }\end{array}$ & $\begin{array}{c}\text { Histomorphometry } \\
\text { cloacal bursa }\end{array}$ \\
\hline & \multicolumn{2}{c}{7 days } \\
\cline { 2 - 3 } Offspring non-supplemented & $0.900 \pm 0.08^{\mathrm{a}}$ & $14.55 \pm 4.97^{\mathrm{b}}$ \\
\hline Offspring supplemented & $0.607 \pm 0.06^{\mathrm{b}}$ & $19.93 \pm 5.50^{\mathrm{a}}$ \\
\hline CV (\%) & 50.43 & 13.79 \\
\hline & $\begin{array}{c}\text { Lymphoid } \\
\text { Clusters }\end{array}$ & $\begin{array}{c}\text { Histomorphometry } \\
\text { cloacal bursa }\end{array}$ \\
\hline Offspring non-supplemented & $1.83 \pm 0.16^{\mathrm{a}}$ & 21 days \\
\cline { 2 - 3 } Offspring supplemented & $1.95 \pm 0.14^{\mathrm{a}}$ & $31.44 \pm 8.25^{\mathrm{a}}$ \\
CV (\%) & 43.78 & 42.35 \\
\hline
\end{tabular}

CV: coefficient of variation. a.b Means within columns with the same superscript are not significantly different $(p<0.05)$

The cloacal bursa consists of lymphocytes encrusted in the epithelial tissue, which folds extend inside the lumen, where they fan out into the lymphoid follicles that contain over $90 \%$ of B cells (Tizard, 1998).

Table 6 shows cell-mediated immune response averages of the offspring fed Arg-supplemented diets, as measured by the injection of phytohemagglutinin (PHA) to stimulate cellular proliferation. It was observed that 12 hours after the PHA injection, there was a quadratic effect with an increase $(p<0.05)$ in the cell-mediated response of broilers fed the diets containing graded levels of Arg. The greatest response was obtained with $1.574 \%$ digestible Arg.

According to Corrier \& DeLoach (1990), this test allows the cell-mediated immune competency to be quickly evaluated. The granules of basophils, cells commonly associated with these processes, contain heparin and proteases, which act intensely in hypersensitivity processes. In addition, they produce cytokines, whose participation is connected to inflammatory processes (Abbas et al., 2007).

The evaluation of macrophage phagocytic activity of the Arg-supplemented offspring evaluated at 35 days of age showed that this function was not affected ( $p>0.05)$ by the graded Arg dietary levels (Table 07). Macrophages are cells of the mononuclear phagocyte system (McCorkle, 1998), part of the innate immunity of poultry and are also important for adaptive immunity (Abbas et al., 2007). They participate in body defense processes by destroying foreign agents and also by secreting cytokines that act in the inflammatory process. The main functions performed by this cell are phagocytosis, destruction of bacteria (Qureshi et al., 1986), secretion of prostaglandins and cytokines, and the provision of antigens to develop cell-mediated immune response (Abbas et al., 2007).

Table 07 - Means and standard deviations of the macrophage phagocytic activity of the broiler chickens fed diets supplemented with graded levels of Arg, at 35 days of age.

\begin{tabular}{lc}
\hline $\begin{array}{c}\text { Arg offspring } \\
\text { diet (\%) }\end{array}$ & $\begin{array}{c}\text { Macrophages with phagocytized erythrocytes/ } \\
\text { Macrophages counted }\end{array}$ \\
\hline 1.300 & $15.70 \pm 5.29$ \\
1.450 & $20.30 \pm 4.80$ \\
1.600 & $16.50 \pm 3.59$ \\
1.750 & $21.50 \pm 5.00$ \\
1.900 & $18.30 \pm 2.50$ \\
\hline CV\% & 5.45 \\
\hline Effect & NS \\
\hline
\end{tabular}

CV: coefficient of variation, $\mathrm{NS}=(p>0.05)$

Offspring antibody titer results are given in Tables 08 and 09. It was found that feeding broiler breeder hens with diets containing graded levels of Arg did not influence the antibody titers $(p>0.05)$ of the offspring fed the diet not supplemented with Arg (Table 08). However, when the diet of the offspring contained graded levels of Arg, there was a decreasing linear effect $(p<0.05)$ at seven days of age, and a quadratic effect $(p<0.05)$ at 28 days of age, with the

Table 6 - Mean and standard deviation of the interdigital reaction to phytohemagglutinin ( $\mathrm{mm}$ ) of the offspring fed with diets containing levels of Arg.

\begin{tabular}{|c|c|c|c|c|}
\hline Arg offspring diet (\%) & 3 hours & 6 hours & 12 hours & 24 hours \\
\hline 1.300 & $1.010 \pm 0.062$ & $0.793 \pm 0.041$ & $0.549 \pm 0.097$ & $0.506 \pm 0.036$ \\
\hline 1.450 & $0.853 \pm 0.077$ & $0.639 \pm 0.065$ & $0.631 \pm 0.051$ & $0.450 \pm 0.133$ \\
\hline 1.600 & $0.918 \pm 0.053$ & $0.738 \pm 0.040$ & $0.702 \pm 0.052$ & $0.543 \pm 0.065$ \\
\hline 1.750 & $0.797 \pm 0.074$ & $0.783 \pm 0.058$ & $0.597 \pm 0.061$ & $0.552 \pm 0.066$ \\
\hline 1.900 & $0.933 \pm 0.044$ & $0.777 \pm 0.038$ & $0.499 \pm 0.059$ & $0,453 \pm 0,062$ \\
\hline CV\% & 17.15 & 16.30 & 27.24 & 38.75 \\
\hline Effect & NS & NS & Quadratic & NS \\
\hline $\mathrm{R}^{2}$ & ----- & ----- & 0.93 & ----- \\
\hline
\end{tabular}

$\mathrm{CV}$ : coefficient of variation, $\mathrm{NS}=(p>0.05){ }^{\prime}{ }^{1} . \mathrm{Y}=2.76361+4.82795 \mathrm{x}-1.69565 \mathrm{x}^{2}$ 
Table 08 - Means and standard deviations of the antibody titers of the non-supplemented offspring, at different ages, from the broiler breeder hens fed with diets containing graded levels of Arg.

\begin{tabular}{|c|c|c|c|c|c|c|c|c|}
\hline \multirow[b]{2}{*}{ Offspring age } & \multicolumn{5}{|c|}{ Arg maternal diet (\%) } & \multirow[b]{2}{*}{$\mathrm{CV}(\%)$} & \multirow[b]{2}{*}{ Effect } & \multirow[b]{2}{*}{$\mathrm{R}^{2}$} \\
\hline & 0.943 & 1.093 & 1.243 & 1.393 & 1.543 & & & \\
\hline 07 days & $3.17 \pm 0.99$ & $3.23 \pm 0.11$ & $3.01 \pm 0.08$ & $3.24 \pm 0.07$ & $3.16 \pm 0.15$ & 8.31 & NS & $\begin{array}{ll}---- \\
\end{array}$ \\
\hline 14 days & $2.62 \pm 0.09$ & $2.57 \pm 0.03$ & $2.42 \pm 0.11$ & $2.62 \pm 0.11$ & $2.57 \pm 0.03$ & 7.92 & NS & ---- \\
\hline 21 days & $2.32 \pm 0.10$ & $2.47 \pm 0.05$ & $2.11 \pm 0.10$ & $2.28 \pm 0.11$ & $2.41 \pm 0.07$ & 9.41 & NS & ----- \\
\hline 28 days & $2.41 \pm 0.28$ & $1.86 \pm 0.14$ & $2.48 \pm 0.22$ & $2.31 \pm 0.19$ & $2.14 \pm 0.24$ & 23.78 & NS & ---- \\
\hline 35 days & $2.75 \pm 0.17$ & $2.84 \pm 0.15$ & $2.71 \pm 0.13$ & $2.86 \pm 0.20$ & $2.91 \pm 0.11$ & 13.61 & NS & ----- \\
\hline
\end{tabular}

CV: coefficient of variation, NS $=(p>0.05)$

highest antibody titer obtained at the level of $1.674 \%$ digestible Arg (Table 09).

As shown in Tables 3 and 5, supplementing the progeny diet with Arg increased the weight and the morphometry of the lymphoid tissue of the bursa of the offspring when compared with the non-supplemented diet. The result observed at 7 days may be correlated with the antibody titer of the Arg-supplemented broilers. Although there was a reduction in the production of antibodies as a function of Arg supplementation, which may be correlated with the neutralization of the maternal antibodies by the application of the vaccine in the offspring, Arg effectively modified the immune response of the supplemented offspring.

After the second vaccination, when birds were 21 days old, there was a positive response of antibody titers to Arg supplementation, again only in the supplemented offspring, showing that the immune response has specific Arg requirements. Very low levels of Arg, about $1.150 \%$, are required to maximize the live performance of broiler chickens in the phase of 21 to 42 days of age (NRC, 1994; Rostagno et al., 2005).

This result is consistent with the observations of other authors. Tayade et al. (2006) demonstrated that the vaccinal response against the infectious bursal disease virus of chickens supplemented with $2 \%$ Arg was $20 \%$ more efficient than the response induced only by the vaccine. The elevated humoral response and the protection observed in the group of vaccinated birds fed a diet supplemented with Arg, according to these authors, may be attributed to the immunoregulatory functions attributed to Arg. Furthermore, according to Abdukalykova \& Ruiz-Feria (2006), added levels of Arg may accelerate antibody production in broiler chickens.

In conclusion, the Arg levels required to optimize the immune response of broiler chickens may be higher than those recommended by NRC (1994) for maximum productive performance. It was found that supplementing the maternal diet with Arg was not sufficient to meet the requirements of the offspring. In contrast, Arg supplementation of the diet of the offspring increased the weight and the morphometry of the lymphoid tissue of the cloacal bursa of the supplemented offspring in comparison with the non-supplemented offspring. The cell-mediated and humoral immune responses of the supplemented offspring were also affected by the dietary addition of Arg. Special attention needs to be given to diet composition, in particular to dietary arginine levels, when broilers are reared in poor environmental, disease challenge, and management conditions.

Improving the performance and health responses of broiler chickens by manipulating maternal diets is a new concept under research because of the economic impact that it may have on total production costs of broiler chickens. The impact of the costs of

Table 09 - Means and standard deviations for the antibody titers of the offspring, at different ages, fed with diets containing graded levels of Arg.

\begin{tabular}{|c|c|c|c|c|c|c|c|c|}
\hline & \multicolumn{5}{|c|}{ Arg offspring diet (\%) } & \multirow[b]{2}{*}{$C V(\%)$} & \multirow[b]{2}{*}{ Effect } & \multirow[b]{2}{*}{$R^{2}$} \\
\hline Offspring age & 1.300 & 1.450 & 1.600 & 1.750 & 1.900 & & & \\
\hline 07 days & $3.31 \pm 0.12$ & $3.36 \pm 0.10$ & $3.01 \pm 0.12$ & $3.29 \pm 0.09$ & $2.99 \pm 0.09$ & 7.98 & Linear $^{1}$ & 0,39 \\
\hline 14 days & $2.26 \pm 0.08$ & $2.18 \pm 0.19$ & $2.19 \pm 0.23$ & $2.07 \pm 0.14$ & $2.45 \pm 0.09$ & 17.15 & NS & ----- \\
\hline \multirow[t]{3}{*}{21 days } & $2.32 \pm 0.07$ & $2.39 \pm 0.06$ & $2.36 \pm 0.06$ & $2.46 \pm 0.12$ & $2.40 \pm 0.09$ & 8.29 & NS & ----- \\
\hline & \multicolumn{5}{|c|}{ Arg offspring diet (\%) } & & & \\
\hline & 1.150 & 1.300 & 1.450 & 1.600 & 1.750 & $\mathrm{CV}(\%)$ & Effect & $\mathrm{R}^{2}$ \\
\hline 28 days & $1.71 \pm 0.35$ & $2.79 \pm 0.09$ & $2.98 \pm 0.06$ & $2.78 \pm 0.19$ & $2.40 \pm 0.12$ & 19.61 & Quadratic $^{2}$ & 0,57 \\
\hline 35 days & $2.68 \pm 0.23$ & $2.99 \pm 0.12$ & $2.96 \pm 0.18$ & $2.80 \pm 0.23$ & $3.13 \pm 0.11$ & 15.35 & NS & ----- \\
\hline
\end{tabular}

CV: coefficient of variation, $N S=(p>0.05) ;{ }^{1} Y=3.93670-0.464676 x ;{ }^{2} Y=-11.4069+18.5064 x-6.07026 x^{2}$ 
manipulating maternal diet nutrients on the total feed costs of broiler production is about $7 \%$, which is very small considering the total feed consumed by the broiler breeder until it is culled.

In the future, due to the growing commercial availability of dietary supplements, synthetic amino acids should become effective nutraceutics for disease prevention and health maintenance of poultry.

\section{ACKNOWLEDGMENTS}

This study was supported by National Council of Technological and Scientific Development (CNPq), Brazil.

\section{REFERENCES}

Abbas AK, Lichtman, AH, Pillai S. Cellular and molecular immunology. $6^{\text {th }}$ ed. Philadelphia: Saunders Elsevier; 2007.

Abdukalykova S, Ruiz Fria C. Arginine and vitamin E improve the cellular and humoral immune response of broiler chickens. International Journal Poultry Science 2006; 5(5):121-127.

Amber IJ, Hibbs JBJ, Parker CJ, Johnson BB, Taintor RR, Vavrin Z. Activated macrophage conditioned medium: Identification of the soluble factors inducing cytotoxicity and the l-arginine dependent effector mechanism. Journal of Leukocyte Biology 1991; 49(6):610-620.

Ball RO, Urschel KL, Pencharz, PB. Nutritional consequences of interspecies differences in arginine and lysine metabolism. Journal of Nutrition 2007; 137(6):1626-1641

Brambell FWR. The transmission of immune globulins from the mother to the foetal and newborn young. Proceedings Nutrition Society $1969 ; 28(1): 35-41$

Bredt DS, Snyder SH. Nitric oxide: a physiologic messenger molecule. Annual review of biochemistry 1994; 63:175-195

Butcher GD, Miles RD. Avian immune system. Veterinary Medicine - Large Animals Clinical Sciences Departament, Florida Cooperative Extension Service, Institute of Food and Agricultural Sciences, University of Florida. VM74; 2003

Calini F, Sirri F. Breeder nutrition and offspring performance. Revista Brasileira de Ciência Avícola 2007; 9(2):77-83.

Corrier DE, De Loach J.R. Evaluation of cell-mediated, cutaneous basophil hypersensitivity in young chickens by an interdigital skin test. Poultry Science 1990; 69 (3):403-408.

De Jonge WJ, Kwikkers KL, Te Velde AA, Van Deventer SJH, Nolte MA, Mebius RE, Ruijter JM, Lamers MC, Lamers WH. Arginine deficiency affects early $B$ cell maturation and lymphoid organ development in transgenic mice. Journal Clinical Investigation 2002; 110(10):15391548.

Gore AB, Qureshi MA. Enhancement of humoral and cellular immunity by vitamin E after embryonic expousure. Poultry Science 1997; 76(7):984991.

Harper AE, Benevenga NJ, Wohlhueter RM. Effects of ingestion of disproportionate amounts of amino acids. Physiological Reviews 1970; 50:428-558.
Hibbs JBJ, Taintor R, Vavrin Z. Macrophage cytotoxicity: Role for I-arginine deiminase and imino nitrogen oxidation to nitrite. Science $1987 ; 235: 473-476$

Jahanian R. Immunological responses as affected by dietary protein and arginine concentrations in starting broiler chicks. Poultry Science 2009; 88(9):1818-1824

Jeurissen SH, Vervelde ML, Janse EM. Structure and function of lymphoid tissues of the chicken. Poultry Science Review 1994;5:183-207.

Kennedy JA, Kirk SJ, Mccrory DC, Halliday MI, Barclay GR, Rowlands BJ. Modulation of immune function and weight loss by L-arginine in obstructive jaundice in the rat. British Journal of Surgery 1994; 81(8):1199-1201.

Kidd MT. Nutritional modulation of immune function in broilers. Poultry Science 2004; 83(4):650-657.

Kobayashi T, Yamamoto M, Hiroi T, McGhee J, Takeshita Y, Kiyono H. Arginine enhances induction of $\mathrm{T}$ helper 1 and $\mathrm{T}$ helper 2 cytokine synthesis by Peyers patch alpha beta $T$ cells and antigen-specific mucosal immune response. Bioscience, Biotechnology and Biochemistry 1998;62(12):2334-2340.

Konjufca VK. Influence of dietary vitamin E on phagocytic functions of macrophages in broilers. Poultry Science 2004; 83(9):1530-1534

Leavy O. T cell responses: A new starting point. Nature Reviews Immunology 2009; 9(7):462-463

Le Floc HN, Melchior D, Obled C. Modification of protein and amino acid metabolism during inflammation and immune system activation. Livestock Production Science 2004; 87(1):37-45

Lewis B, Langkamp-Henken B. Arginine enhances in vivo immune responses in young, adult and aged mice. Journal of Nutrition 2000; 130(7):18271830

Löser C, Eisel, A Harms D, Foëlsch UR. Dietary polyamines are essential luminal growth factors for small intestinal and colonic mucosal growth and development. Gut 1999; 44(1):12-16.

Mccorckle FM. Introduction to the symposium: nonlymphoid cells and their factors in immune response. Poultry Science 1998; 77(7):963.

Morgulis MS. Imunologia Aplicada. In: Macari M, Furlan RL, Gonzáles E, editores. Fisiologia Aviária Aplicada a Frangos de Corte. Jaboticabal: Funep-Unesp; 2002. p. 231-2452

Munir K, Muneer MA, Masaoud E, Tiwari A, Mahmud A, Chaudhry RM, Rashid A. Dietary arginine stimulates humoral and cellmediated immunity in chickens vaccinated and challenged against hydropericardium syndrome virus. Poultry Science 2009;88(8):16291638

Newsholme P, Brennan L, Rubi B, Maechler P. New insights into amino acid metabolism, beta-cell function and diabetes. Clinical Science 2005;108(4):185-194

National Research Council. Nutrient requirements of poultry. $9^{\text {th }}$ rev ed.Washington: National Academy Press; 1994

Ochoa JB, Strange J, Kearney P, Gellin G, Endean E, Fitzpatrick E. Effects of I-arginine on the proliferation of $\mathrm{T}$ lymphocyte subpopulations. Journal of Parenteral and Enteral Nutrition 2001;25(1):23-29.

Qureshi MA, Dieteri RR, Bacon LD. Genetic variation in the recruitment and activation of chicken peritoneal macrophages. Experimental Biology and Medicine 1986, 181(4):560-568.

Rostagno HS, Albino LFT, Donzele JL, Gomes PC, Oliveira RFM, Lopes DC, Ferreira AS, Barreto SLT. Tabelas brasileiras para aves e suínos: 
composição de alimentos e exigências nutricionais. $2^{\text {nd }}$ ed. Viçosa: UFV; 2005.

Smith NC, Wallach M, Miller CMD, Morgenstern R, Braun R, Eckert J. Maternal transmission of immunity to Eimeria maxima: ELISA analysis of protective antibodies induced by infection. Infection and Immunity 1994;62(11):4811-4817

Tayade C, Jaiswal TN, Mishra SC, Madhuri K. L-Arginine stimulates immune response in chickens immunized with intermediate plus strain of infectious bursal disease vaccine. Vaccine 2006;24:552-560.

Tizard IR. Imunologia veterinária. $5^{\text {th }}$ ed. São Paulo: Roca; 1998

Tressler R L, Roth TF. IgG receptors on the embryonic chick yolk. The Journal of Biological Chemistry 1987;262(32):15406-15412.
Tsai HJ, Shang, HF, Yeh CL, Yeh SL. Effects of arginine supplementation on antioxidant enzyme activity and macrophage response in burned mice. Burns 2002; 28:258-263.

Uni Z, Ferket RP. Methods for early nutrition and their potential. World's Poultry Science Journal 2004;60(1):101-111.

Universidade Federal de Viçosa. SAEG; sistema de análises estatísticas e genéticas: manual do usuário. Versão 7.1. Viçosa: UFV; 1997.

Wu G, Bazer FW, Davis TA, Kim SW, Li P, Rhoads JM, Satterfield MC, Smith $S B$, Spencer TE, Yin Y. Arginine metabolism and nutrition in growth, health and disease. Amino Acids 2009;37(1):153-168 